\title{
TRAÇOS DA LINGUAGEM FOTOGRÁFICA EM LA ISLA $A$ MEDIODÍA
}

Resumo: Dentro da obra de Julio Cortázar, encontramos inúmeros textos que compõem diversos gêneros como poesia, conto, romance, ensaio, teatro e outros que, muitas vezes, são de difícil classificação. Nesse universo, a literatura cortazariana chama atenção pela grande quantidade de imagens que sugere, mesmo frente a temáticas que soam abstratas e complexas. Dos elementos que se repetem nos textos desse escritor, a fotografia é um deles. Além da relação pessoal de Cortázar com a câmera fotográfica, em um de seus ensaios, o escritor propôs uma reflexão acerca do conto e sua ligação com a fotografia. Para ele, a estrutura de um conto se aproxima à estrutura da fotografia, pois ambos seguem padrões semelhantes, embora tenham origens bem distintas. Além disso, o modo com que escreve seus contos, pressupõe a presença não apenas de um escritor, mas a de um fotógrafo que compõe, enquadra, analisa e recorta sua narrativa. Para ilustrar essa ideia, o presente trabalho busca analisar o conto La isla a mediodía (1966), de Julio Cortázar, sob a ótica da fotografia, mas sem ignorar seu viés fantástico. Tal conto oferece inúmeras possibilidades para que se possa estabelecer essa discussão, já que o olhar, um dos elementos mais presentes no campo fotográfico, perpassa toda a narrativa a partir das atitudes do protagonista Marini. Seu ponto de vista, em relação a tudo o que observa, pode ser comparado ao de um fotógrafo que, por via da câmera, olha, seleciona e narra por meio das imagens registradas.

Palavras-chave: Fotografia; Julio Cortázar; Literatura.

Resumen: En la obra de Julio Cortázar, encontramos innúmeros textos que componen diversos géneros como poesía, cuento, novela, ensayo, teatro y otros que, a veces, son difíciles de clasificar. Ante este universo, la literatura cortazariana llama la atención por la cantidad de imágenes que sugiere, mismo cuando aborda temas abstractos y complejos. De los elementos que se repiten en los textos del escritor, la fotografía es uno de

${ }^{48}$ Doutora em Literatura Comparada pela Universidade Federal do Rio Grande do Sul-UFRGS. Professora do Instituto Federal Catarinense- Campus Blumenau. 
los principales. Además del contacto personal de Cortázar con la cámara fotográfica, en uno de sus ensayos, propuso una reflexión acerca del cuento y la relación con la fotografía. Para él, la estructura de un cuento se acerca a la de una foto, pues, ambos siguen patrones semejantes, aunque tengan orígenes distintos. Además de eso, el modo como Cortázar escribe sus cuentos, evoca la presencia no sólo de un escritor, sino también de un fotógrafo que compone, encuadra, analiza y recorta su narrativa. Para ilustrar esa idea, el presente trabajo busca hacer un estudio de La isla a mediodía (1966), de Julio Cortázar, bajo la mirada fotográfica, pero sin rechazar lo fantástico. Tal cuento ofrece muchas posibilidades para entablar esa discusión, ya que la mirada, uno de los elementos más importantes del campo fotográfico, ultrapasa tal narrativa a partir del espacio y de las actitudes del protagonista Marini. Su punto de vista puede ser comparado al de un fotógrafo que, a través de la cámara, mira, elige, selecciona y narra por medio de imágenes.

Palabras clave: Fotografía; Julio Cortázar; Literatura.

\section{Introdução: Cortázar e a fotografia}

Analisar a obra de Julio Cortázar se assemelha a mergulhar num oceano, não apenas pela extensão física do material produzido, mas pelas inúmeras possibilidades de leitura que seus escritos nos possibilitam. Seus inúmeros textos variam quanto à extensão, ao gênero, à complexidade narrativa e à temática, deixando qualquer leitor com a impressão de que está diante de um imenso mosaico literário. $\mathrm{O}$ menino que nasceu em Bruxelas, em 1914, e viveu diversos anos na Argentina e na França, veio a falecer, em 1984, na cidade de Paris (MATURO, 2014). Suas experiências com o mundo das letras foram bastante precoces. Em uma das inúmeras entrevistas concedidas, Cortázar revelou:

Mis primeros libros me los regaló mi madre. Fui un lector muy precoz y, en realidad, aprendí a leer por mi cuenta, con gran sorpresa de mi familia, que incluso me llevó al médico porque creyeron que era una precocidad peligrosa [...]. Muy pronto me dediqué a sacar los libros que encontraba en las bibliotecas de la casa. Con lo cual muchas veces leí libros que estaban al margen de mi 
comprensión a los siete, ocho, nueve años de edad (CORTÁZAR In: CRESPO, 1995, p. 85). ${ }^{49}$

O gosto pela leitura e, também, pela escrita, como afirmou diversas vezes, certamente, contribuiu para a formação do escritor que publicou seus primeiros poemas sob o pseudônimo Julio Denis na Revista Presença, passando a assumir, posteriormente, o nome Julio Cortázar nos textos publicados. (LA NACIÓN, 2006). Quando lemos as cartas, os contos, os ensaios e outros escritos, percebemos que, de alguma forma, ali estão consolidados fragmentos da vida de Cortázar, que resultam da experiência de inúmeros movimentos ou processos. O modo de ser e de pensar transpareciam em cada trama ficcional. A literatura era o resultado da própria vida.

Na obra publicada sobre o escritor, em 2014, Cortázar de la A a la Z - un álbum biográfico, organizada por Aurora Bernárdez y Carles Álvares de Garriga, fica evidente esse mosaico entre o que escrevia e o que vivia Cortázar. Pode-se dizer que é um dos materiais que melhor mostra quem realmente foi esse escritor, pois traz o todo a partir de pequenos fragmentos: trechos de obras, manuscritos, imagens de sua vida pessoal, lugares por onde passou, pessoas com quem esteve, prazeres dos quais desfrutou.

Ao estabelecermos contato com a obra de Julio Cortázar, ainda que tenhamos parcos conhecimentos sobre os temas comumente abordados, fica evidente a forte relação com temas como o boxe, o jazz, a fotografia, entre outros. Se lermos apenas os primeiros livros de contos publicados pelo autor, já são suficientes para observarmos a força com que esses assuntos alcançam a sua literatura. Muitas das afirmações feitas por personagens cortazarianos podem ser entendidas como se fossem a voz do próprio Cortázar se manifestando. De um modo geral, é bastante perceptível, na obra de Cortázar, a presença de imagens que se formam por meio das palavras. As descrições dos fatos, personagens e espaços aparecem sempre de forma muito clara. Tal aspecto é bastante coerente com uma das declarações feitas por Cortázar em entrevista concedida ao uruguaio Omar Prego (1991). Ele afirmou que a escrita de contos partia

\footnotetext{
49 Segundo o editor, Antonio L. Crespo, a entrevista intitulada Cortázar lector Conversación con Julio Cortázar foi concedida, em 1976, a Sara Castro-Klaren e publicada, em 1980, nos Cuadernos Hispanoamericanos, n. 364 - 366, outubro a dezembro de 1980.
} 
sempre de uma ou diversas imagens, ou seja, as palavras acabavam se configurando na formalização dessas imagens.

Quanto à presença, em especial, da fotografia, mencionada anteriormente, queremos destacar algumas das obras que salientam a presença desse elemento. Em Las babas del diablo (1959), o protagonista Roberto Michel, a certa altura do conto, declara:

Entre las muchas maneras de combatir la nada, una de las mejores es sacar fotografías, actividad que debería enseñarse tempranamente a los niños pues exige disciplina, educación estética, buen ojo y dedos seguros. No se trata de estar acechando la mentira como cualquier repórter, y atrapar la estúpida silueta del personajón que sale del número 10 de Downing Street, pero de todas maneras cuando se anda con la cámara hay como el deber de estar atento, de no perder ese brusco y delicioso rebote de un rayo de sol en una vieja piedra, o la carrera trenzas al aire de una chiquilla que vuelve con un pan o una botella de leche (CORTÁZAR, 1971, p. 81).

Tal conto, que inspirou o filme Blow up - depois daquele beijo, de 1966, do diretor Michelangelo Antonioni, tem a fotografia como elemento em torno do qual se desenvolve a narrativa.

Em Rayuela (1963), um dos grandes romances cortazarianos, o narrador estabelece uma reflexão a partir da qual menciona o álbum de fotos:

En alguna parte Morelli procuraba justificar sus incoherencias narrativas, sosteniendo que la vida de los otros, tal como nos llega en la llamada realidad, no es cine sino fotografía, es decir que no podemos aprehender la acción sino tan sólo sus fragmentos eleáticamente recortados. No hay más que los momentos en que estamos con ese otro cuya vida creemos entender, o cuando nos hablan de él, o cuando él nos cuenta lo que le ha pasado o proyecta ante nosotros lo que tiene intención de hacer. Al final queda un álbum de fotos, de instantes fijos; jamás el devenir realizándose ante nosotros, el paso del ayer al hoy, la primera aguja del olvido en el recuerdo (CORTÁZAR, 1996, p. 386). 
Já, em Prosa do observatório (1972), fotografias aparecem inseridas em meio ao texto e foram tiradas pelo próprio Cortázar, em 1968, nos observatórios do sultão Jai Singh em Delhi, com a participação de Antonio Gálvez (CORTÁZAR, 1974, p. 7). Tais imagens retratam alguns dos espaços visitados e se mesclam com o texto ensaístico, preenchendo as páginas da obra.

Outra obra relacionada com o elemento fotográfico é Los autonautas de la cosmopista (1983), resultado de uma aventura realizada entre Cortázar e sua esposa na época, a fotógrafa Carol Dunlop. Ambos colocaram em prática um jogo que consistiu em percorrer o trecho entre Marselha e Paris durante trinta e três dias, registrando suas experiências cotidianas por meio das imagens e da escrita.

Diante desse contexto, também vale ressaltar a participação e colaboração de Julio Cortázar nas obras Buenos Aires, Buenos Aires (1968) e Humanario (1976), dois fotolivros produzidos por Sara Facio e Alicia D'Amico, as quais convidaram o escritor para produzir uma série de textos que estabelecessem relação com as fotografias que haviam tirado, de acordo com a temática de cada um dos livros (TOMASI, 2013).

Ademais das relações mostradas acima, o escritor franco-argentino não ressaltou a presença da fotografia apenas em sua produção ficcional. Muitos conhecem a aproximação que Cortázar estabeleceu entre romance e cinema e entre conto e fotografia no ensaio Algunos aspectos del cuento escrito em 1963. No referido texto, ele afirmou que em termos de estrutura e extensão, um romance poderia ser comparado a um filme, pois seu desenrolar se dá sem grandes preocupações, tendo em vista o tempo e o espaço, razoavelmente amplos, que o favorecem. Já o conto, nesse sentido, se compararia à fotografia pelo limite temporal e espacial que o controlam. Esse paralelo, mais que a teoria sobre o ato de escrever, pode ser entendido como um dos eixos que sustentam, até hoje, a aproximação entre conto e imagem fotográfica, asseverando um entrosamento entre as duas artes. Sabemos que fotografia e conto possuem aspectos idiossincráticos, ou seja, que são próprios do modo de produção, no entanto, não impede que um encontre no outro, elementos correspondentes.

Ao falarmos de fotografia, encontramos componentes indissociáveis à técnica e ao contexto como, por exemplo, o ponto de vista, a luz, os planos, o foco, a profundidade de campo, o 
enquadramento, a composição, entre outros ${ }^{50}$. Por outro lado, diante das narrativas ficcionais escritas, temos elementos próprios como o narrador, o tempo, o espaço, os personagens, para citar alguns. No caso do conto, especificamente, esses elementos costumam ser bastante condensados e o contista precisa saber exatamente o que mostrar ou ocultar, tendo em vista que está diante de uma narrativa curta. Segundo Piglia (1994), um conto sempre conta duas histórias. Uma história visível sempre oculta outra secreta. Para ele, a história secreta é construída a partir do não dito, do subentendido e da alusão. Nos contos de Cortázar, em geral, podemos observar uma proximidade bastante estreita com os elementos que seriam próprios da fotografia, justamente pela sua estrutura ${ }^{51}$. Esse é o assunto que nos interessa neste trabalho. Para tal, discutiremos o conto La isla a mediodia, que faz parte do livro Todos los fuegos el fuego (1966), com o intuito de buscar e analisar esse estreitamento com o contexto fotográfico.

O conto em questão faz parte do conjunto de narrativas fantásticas cortazarianas, que propõe a sucessão de alguns fatos cuja reação, tanto dos personagens quanto do leitor, é de estranhamento e desconforto diante do caos que se instala num ambiente considerado real e comum. Dentre os diversos teóricos que debateram sobre o fantástico, Alazraki (1990) afirma que, especificamente na Argentina, o termo "literatura fantástica" foi usado de maneira ambígua. Para ele, alguns autores escreviam contos inseridos dentro desse gênero, mas sem a presença de elementos puramente fantásticos como o horror e o medo, o que fez com que propusesse a denominação neofantástico para identificar esse tipo de narrativas escritas após o século XIX. Nesse grupo, encaixam-se os contos de Jorge Luis Borges, Bioy Casares e Julio Cortázar, por exemplo. Assim, ainda que haja uma distinção teórica, frequentemente encontramos as narrativas cortazarianas classificadas, em geral, como literatura "fantástica" em vez de "neofantástica". Tal esclarecimento é feito para

\footnotetext{
${ }^{50}$ Para compreender melhor esses conceitos, sugerimos consultar a obra Falando fotograficamente (2015), de David DuChemin, tradução de Raphael Boneli, publicado pela Editora Photos. O autor, além de elucidar o conceito de inúmeros termos, exemplifica por meio de fotografias, tornando a compreensão bastante clara.

51 Para maiores informações e reflexões acerca dessa aproximação, sugerimos a leitura da tese de doutorado intitulada Paralelos entre a técnica compositiva do conto e da fotografia nas obras "Bestiario", "Final del juego" e "Las armas secretas", de Julio Cortázar, (SAVARIS, 2017. Disponivel em:< http://hdl.handle.net/10183/170433 >.
} 
melhor contextualizar a narrativa, já que tanto uma classificação quanto a outra, não interferem diretamente na análise que faremos em seguida. $\mathrm{O}$ conto La isla a mediodía tem uma relação intensa com a imagem e com o olhar, e embora tenha essa relação com o viés fantástico, nosso estudo será sob a ótica da fotografia e os elementos que a compõem.

\section{La isla a mediodía: literatura e fotografia}

O referido conto nos apresenta a história de Marini, auxiliar de voo numa linha aérea que faz o percurso Roma - Teerã - Roma, cujo trabalho é bastante monótono. Diante dessa rotina, Marini passa longos minutos olhando pela janela do avião em busca de algo que possa romper o marasmo. Numa das viagens, ao sobrevoar o mar Egeu no horário do meio-dia, Marini fixa seu olhar numa pequena ilha chamada Xiros, pela qual sente uma imensa atração. Chama-lhe a atenção a cor da água, as pedras que a contornam e o fato de ser solitária. Quatro dias depois, ao fazer o retorno pelo mesmo trajeto e praticamente no mesmo horário, novamente, Marini se inclina e olha pela janela do avião, avistando outra vez a ilha. Agora, seu olhar confirma um dado novo: a ilha possui o formato de uma tartaruga. A imagem vai ficando cada vez mais presente na mente de Marini, ainda que seu tamanho diminua conforme o avião vai se afastando dela.

Essas são as primeiras informações que chegam ao conhecimento do leitor se dão a partir do olhar de Marini que está dentro do avião. A pequena janela funciona exatamente como uma objetiva e os olhos do auxiliar de voo se assemelham aos de um fotógrafo que enquadra a paisagem no visor da câmera para efetuar o registro. Ao analisarmos a imagem fotográfica em termos de condições de produção, um dos primeiros aspectos que está ligado a isso é o chamado autor empírico, denominação usada por Javier Marzal Felici (2011) no livro Cómo se lee una fotografia. O fotógrafo, ao apoderar-se da câmera, enquadra e registra a imagem a partir do seu ponto de vista, escolhendo, de acordo com os seus objetivos para aquele momento, o que deseja realçar ou minimizar, cabendo ao espectador dessa imagem um produto determinado pelo autor empírico. Para Jacques Aumont (1953, p. 59) "o olhar é o que define a intencionalidade e a finalidade da visão". No conto La isla a mediodía, esse papel é preenchido pelo narrador que escolhe o rumo daquilo que está narrando. Segundo Alberto Paredes (1988, p.76-77), “[...] se va haciendo claro que el narrador elige con plena deliberación sus casos y objetivos literarios. Escoge y privilegia personajes en apariencia normales, pero 
184 | Michele Savaris

provistos de cierta singularidad [...]". E acrescenta: "El narrador es el personaje que observa aquello casi en una contiguidad física los sucesos, y nosotros leemos la transferência verbal directa de lo que él observa a través de su ventana" (PAREDES, 1988, p. 77-78). No âmbito da fotografia, a forma de determinar o conjunto das informações pode ser comparada com o ponto de vista que o fotógrafo escolhe durante o processo de enquadramento da imagem desejada. Em La isla a mediodía, o modo como as informações chegam ao leitor simula a presença de uma câmera que, embora conduzida pelo narrador, tem a clara intenção de registrar o entorno e/ou a visão do protagonista Marini:

Marini se demoraba ajustando la mesa, preguntándose aburridamente si valdría la pena responder a la mirada insistente de la pasajera, una americana de las muchas, cuando en el óvalo azul de la ventanilla entró el litoral de la isla, la franja dorada de la playa, las colinas que subían hacia la meseta desolada. Corrigiendo la posición defectuosa del vaso de cerveza, Marini sonrió a la pasajera (CORTÁZAR, 2004, p. 147).

Entre a janela do avião e a ilha, é estabelecida uma conexão que depende, fundamentalmente, do olhar. Ao acompanharmos o olhar, que faz as vezes da objetiva de uma câmera, a paisagem ganha um dinamismo em função da sua descrição:

[...] se concedió unos segundos para mirar otra vez hacia abajo; la isla era pequeña y solitaria, y el Egeo la rodeaba con un intenso azul que exaltaba la orla de un blanco deslumbrante y como petrificado, que allá abajo sería espuma rompiendo en los arrecifes y las caletas. Marini vio que las playas desiertas corrían hacia el norte y el oeste, lo demás era la montaña entrando a pique en el mar. Una isla rocosa y desierta, aunque la mancha plomiza cerca de la playa del norte podía ser una casa, quizá un grupo de casas primitivas (CORTÁZAR, 2004, p. 148).

As informações que nos chegam passam pelos olhos do protagonista, o que significa que estamos diante do chamado discurso indireto livre e por meio dele "vemos coisas através dos olhos e da linguagem do personagem [...]" (WOOD, 2011, p. 25). Se transportarmos 
esse aspecto para o campo da fotografia, podemos dizer que a visão relatada pelo narrador pode ser entendida como os planos de uma imagem fotográfica. Para Felici,

La percepción de los planos en una imagen viene dada por dos elementos: la superposición de las figuras del encuadre, lo que permite distinguir entre objetos y sujetos situados más cerca o más lejos del punto de observación; y por el aspecto proyectivo, es decir, por su disposición desde un ángulo determinado (FELICI, 2011, p. 183).

A distância física existente entre os olhos de Marini e os objetos ou indivíduos que se encontram na ilha, é imensa. Isso resulta numa diferença lógica de tamanho, ou seja, o que está mais distante do observador é visto em tamanho mais reduzido, chegando a gerar dúvida do que realmente poderia ser aquela mancha próxima da praia: uma casa ou, talvez, um grupo de casas primitivas. Essa relação entre o que está próximo e o que está distante do espectador também se faz presente no trecho em que se supõe que Marini, obsessivo pela imagem da ilha, teria descido até ela, e ao observar uma embarcação no mar a partir do ponto onde se encontra, afirma: "casi en el horizonte la falúa se iba empequeñeciendo” (CORTÁZAR, 2004, p. 157). Todo e qualquer registro fotográfico envolve essa relação de distância e proximidade que se dá a partir do olho (ou da câmera) de quem fotografa, tendo, muitas vezes, que utilizar recursos técnicos do próprio equipamento para aproximar objetos que estão longe, de modo a torná-los mais visíveis aos olhos do espectador ou fotógrafo. Esse recurso chama-se $z o o m^{52}$ e gera um efeito, frente aos olhos, de aproximação dos objetos ou partes e uma consequentemente sensação de ampliação daquilo que está distante.

Em La isla a mediodía, diante de toda essa paisagem que Marini vê por meio da janela do avião, percebe-se o tempo todo o enquadramento da imagem, "o campo visto sob determinado ângulo e com determinados limites exatos" (AUMONT, 1993. p. 153). Após longos minutos de enquadramento do olhar contemplativo de Marini sobre a imagem que avista, enquadrando-a e analisando-a, o narrador do conto afirma: "cuando se inclinó sobre una ventanilla de la cola no le quedaron dudas; la isla tenía una forma inconfundible, como una tortuga que sacara

52 Aumont (1993) e outros teóricos do campo da imagem nos explicam que o recurso do zoom é possível em objetivas de foco variável. 
186 | Michele Savaris

apenas las patas del agua" (CORTÁZAR, 2004, p. 148). A relação de semelhança que Marini estabelece entre a ilha e uma tartaruga pode ser associada ao ponto de vista, ou seja, a maneira como são vistos os objetos e espaços a partir do lugar de onde parte esse olhar. De acordo com uma das concepções de Aumont (1993, p. 156), seria "o modo particular como uma questão é considerada”. O fotógrafo, ao colocar-se diante de uma cena, enquadra-a a partir da posição que ele ocupa e do ponto de vista que possui sobre o que está avistando. Muitas imagens fotográficas permitem que o fotógrafo as associe metaforicamente a referências préexistentes, gerando um processo de metamorfose a partir dessa visão subjetiva. O mesmo ocorre com Marini em La isla a mediodía, ao associar a imagem da ilha (objeto real) com uma tartaruga (referência pré-existente). A partir desse momento, a ilha ganha outro significado para o produtor da imagem. $\mathrm{O}$ ato de identificar uma tartaruga a partir da imagem da ilha, pode ser associado com o que Felici (2011, p. 186) chama de forma, ou seja, "se refiere al conjunto de características que se modifican cuando el objeto visual cambia de posición, orientación o, simplemente, de contexto". A mudança de posição tem a ver, também, com o ponto onde o fotógrafo se encontra no momento em que lança seu olhar sobre o objeto ou espaço.

A cada viagem realizada sobre a ilha, Marini se sentia mais próximo dela, embora a distância real fosse imensa. $O$ ato de olhar constantemente pela minúscula janela do avião deixa clara uma conexão íntima entre o protagonista e a paisagem, assemelhando-se a um fotógrafo atrás da lente que ao clicar e registrar a cena estabelece uma relação indissociável com ela.

Ao longo da leitura do conto, podemos observar que a melhor visão que Marini possui da ilha ocorre, justamente, nos horários próximos ao meio-dia, talvez, porque a incidência solar é vertical e direta com o mínimo possível de formações sombrias. Uma das imagens descritas pelo auxiliar de voo ao sobrevoar Xiros, faz referência a um mar azul intenso cuja orla apresenta um branco deslumbrante na qual a espuma se rompe nos recifes e nos pequenos barcos, além de verdes horizontes. O narrador afirma que Marini: "Miró su reloj pulsera sin saber por qué; era exactamente mediodía" (CORTÁZAR, 2004, p. 148). O horário mencionado funciona, sem dúvidas, como um localizador no tempo, mas não podemos deixar de reconhecer que, sob a ótica da fotografia, ele também determina condições de luz.

Em outro fragmento, temos a informação de que o protagonista de La isla a mediodía está sobrevoando Xiros pela manhã. Tal dado nos 
permite destacar, portanto, a presença da luminosidade que incide sobre a cena vista a partir da janela do avião e, também, a relação das cores descritas e os contrastes gerados. Ambos os aspectos estão estreitamente relacionados no contexto fotográfico. Sobre o primeiro ponto, Javier Marzal Felici afirma:

La luz es quizás el elemento morfológico más importante que cabe destacar en el estudio de la imagen. La luz es la materia primogenia con la que se construye cualquier imagen. No en vano la fotografía es, como nos indica la etimologia del término, una "escritura de la luz" (FELICI, 2011, p.189).

Diversas vezes, em La isla a mediodía, se observa a importância da luz para os olhos de Marini, pois sua escassez compromete a realidade da imagem que o espectador produz, ou ainda, quando a incidência dessa luz não está na direção adequada, também pode conturbar a visão.

En los viajes de vuelta el avión sobrevolaba Xiros a las ocho de la mañana; el sol daba contra las ventanillas de babor y dejaba apenas entrever la tortuga dorada; Marini prefería esperar los mediodías del vuelo de ida, sabiendo que entonces podía quedarse un largo minuto contra la ventanilla [...] (CORTÁZAR, 2004, p. 152).

No horário das oito da manhã, a incidência da luz sobre a janela do avião não favorecia a visão de Marini em direção a Xiros, fazendo com que a ilha em forma de tartaruga mal pudesse ser vista ${ }^{53}$. Sem dúvidas, as

${ }^{53}$ Vale ressaltar, aqui, um esclarecimento acerca do termo "apenas" presente no fragmento acima "[...] el sol daba contra las ventanillas de babor y dejaba apenas entrever la tortuga dorada; [...]”. Em consulta ao dicionário online da Real Academia Espanhola (www.rae.es) e ao dicionário Señas (2002) encontramos as seguintes acepções para o termo: "1. adv. Casi no" (RAE) e "1.adv. Con dificultad; casi no" (SEÑAS). Na língua portuguesa, o termo "apenas” significa "somente". Na tradução para o português do conto La isla a mediodía feito por Gloria Rodrígues (In: Todos os fogos o fogo - Ed. Civilização Brasileira, 1974, encontramos "[...] o sol batia nas janelas de bombordo e apenas deixava entrever a tartaruga dourada;" (p. 96). Podemos observar que no texto original a ideia é a de que o sol incidia contra a janela e a ilha mal podia ser vista. Já, na tradução ao português, a ideia é a de que o sol incidia contra a janela e somente deixava ver a 
diversas menções feitas ao sol, ao longo da narrativa, demonstram a saliência desse elemento que atua sobre os corpos e os espaços modificando-os. Nesse contexto, a luz solar parece adquirir a mesma importância que a luz possui no ato fotográfico. A percepção das formas, das texturas e das cores só é possível pela existência da luz (FELICI, 2011). No conto cortazariano que estamos analisando, essa iluminação proveniente do sol permite que Marini perceba e descreva as cores e as formas de tudo o que está enquadrado no seu campo de visão.

A luminosidade também interfere nos contrastes. "El contraste del sujeto o del motivo fotográfico corresponde a la diferencia de niveles de iluminación reflejada (luminancia) entre las sombras y la altas luces" (FELICI, 2011, p. 190). Quando Marini relata, de dentro do avião, o intenso azul do mar, o branco da espuma e o verde do horizonte, o faz em função das condições de luminosidade que permitem essa diferenciação. No âmbito da fotografia, o produtor da imagem sabe e reconhece a importância de lidar com a quantidade ideal de luz que entra pelo diafragma da câmera no ato do registro. No caso de Marini, sempre que a luz solar incidia favoravelmente sobre Xiros, sua visão era bastante clara.

Em certa passagem do conto, pela voz do narrador tomamos conhecimento que, certa vez, Marini "sacó una foto de Xiros, pero le salió borrosa” (CORTÁZAR, 2004, p. 152). Este ato parece configurar o auge de toda a relação que o personagem estabelece com a fotografia, ou seja, ele assume o lugar do fotógrafo. Como ocorre, eventualmente, com todo e qualquer fotógrafo, a imagem pode sofrer deslizes no processo, comprometendo a nitidez da imagem.

Sin duda, la nitidez o borrosidad de la imagen es un recurso expresivo con una dimensión objetiva que, en ocasiones, puede encerrar una variedad de significaciones notable, en especial cuando se combina con la utilización de otros recursos. [...] la nitidez de la imagen está estrechamente vinculada al trabajo sobre el grano (o el pixel) fotográfico, es decir el concepto de textura. El control

ilha (grifo meu). Para a discussão proposta, neste artigo, com relação ao conteúdo do fragmento, meu argumento está totalmente respaldado pela acepção do termo "apenas" do texto original. No entanto, tal argumento não se sustentaria se utilizássemos o texto em português por conta da interpretação proposta pela tradução. 
del enfoque es una técnica que permite destacar una figura sobre un fondo de la imagen (FELICI, 2011, p. 188).

A partir dessa explicação técnica, é possível compreender melhor o resultado da atuação de Marini na condição de alguém que fotografa a cena. Diversas são as causas que podem levar uma fotografia à falta de nitidez, seja por configuração inadequada da câmera ou por descuido do fotógrafo no instante do clique. Vale lembrar que quanto melhor apoiada e estática estiver a câmera, mais condições de foco e nitidez terá a imagem fotográfica.

O protagonista de La isla a mediodía se encontra numa posição bastante favorável do ponto de vista de um fotógrafo, pois possui uma visão ampla a partir do espaço que ocupa dentro do avião e pode escolher o que deseja registrar. Ainda que muitos dos objetos resultem minúsculos devido à distância, é possível perceber que o protagonista fixa seu olhar em muitos desses objetos detalhando-os como se eles ganhassem uma outra dimensão frente aos seus olhos, ou seja, ao final da narrativa, todos aqueles minúsculos objetos de Xiros vão ganhando uma dimensão real frente os olhos de Marini, até nos darmos conta que o avião está sofrendo uma queda. As pequenas casas, as pessoas, os barcos, passam a ficar próximos dos olhos que os contemplou à longa distância por tantas vezes. No fragmento: "la isla lo invadía y lo gozaba con una tal intimidad" (CORTÁZAR, 2004, p. 155), o processo sofre uma inversão de modo que a ilha parece ir em direção a Marini e não Marini em direção à ilha, como o conto propunha até o momento. Sob o ponto de vista da fotografia, sempre que aplicamos o recurso do zoom ou da macrofotografia e, portanto, ampliamos determinados detalhes ou pontos de uma cena, é como se a imagem apontada pela objetiva viesse ao encontro do fotógrafo que está parado manuseando o equipamento. A cena registrada na imagem passa a apresentar dimensões bem mais amplas que aquelas permitidas pela visão quando o referente e a objetiva se encontram a uma distância muito grande um do outro. Nesse sentido, se Marini pode ser associado a um fotógrafo pelo modo como se relaciona com a ilha que avista de dentro do avião, o cadáver estendido sobre a areia, que tem os olhos fechados por ordem de uma das mulheres da ilha, indica o encerramento desse possível processo fotográfico cujos traços apontamos 
190 | Michele Savaris

ao longo de nossa análise. Os olhos fechados representam a escuridão e sem luz não há fotografia. ${ }^{54}$

\section{Considerações finais}

A exaltação do olhar percorre todo o conto La isla a mediodía. Como um dos principais aspectos que sustentam o tema da fotografia, o olhar é tratado como pilar de sustentação, tanto no que diz respeito à figura em si do protagonista Marini quanto naquilo que se relaciona com ele. $\mathrm{O}$ ver se coloca como cerne da narrativa, segundo o viés pelo qual a analisamos. Fragmentos como "Marini vio que las playas desiertas corrían hacia el sur y hacia el norte" (CORTÁZAR, 2004, p. 148), "es como si Marini ahora tuviera contacto con lo que antes sólo miraba desde el avión" (CORTÁZAR, 2004, p. 150), "mirando salir el sol sobre un mar menos oscuro" (CORTÁZAR, 2004, p. 155), "Miró verticalmente el cielo" (CORTÁZAR, 2004, p. 158), "Klaios miró hacia el mar" (CORTÁZAR, 2004, p.160), exaltam a sensibilidade e o olhar, tão essenciais para o campo da fotografia. Para Barthes (1984), a fotografia tem relação com o espetáculo, ou seja, não apenas o Operator (termo usado para se referir ao fotógrafo) se utiliza do olhar para produzi-la, mas os espectadores também necessitarão dele para ver, observar e analisar o que foi produzido. Assim, ainda que no presente trabalho estejamos privilegiando a ação de Marini com relação aos aspectos fotográficos, é indispensável pensar que, do outro lado da narrativa, o leitor acaba ocupando o espaço desse alguém que entra em contato com o que está sendo produzido e formalizado por meio do olhar do fotógrafo.

Diante da ênfase que estamos dando no que se refere ao ato de ver frente ao contexto fotográfico, cabe realçar que também o que está oculto na fotografia contribui para a sua composição. Assim, da mesma forma que o olhar de Marini sobre a ilha nos direciona e nos coloca como cúmplices das imagens que registra a partir de seus olhos (e de sua câmera ao fotografar Xiros), também há muitas coisas que ele oculta, seja por vontade própria ou por, simplesmente, não serem compatíveis com as questões de enquadramento da fotografia. Desse modo, ocultar também

\footnotetext{
${ }^{54}$ Vale esclarecer que, do ponto de vista fantástico, ocorre uma dilatação temporal e o tempo da narrativa é exatamente o mesmo da queda do avião. Esse recurso da dilatação temporal também se dá em outros textos de Cortázar. Dessa forma, Marini só aparece na ilha como cadáver após a queda do avião.
} 
significa valorizar determinados níveis do ato de ver no sentido de concentrar os olhos em aspectos considerados especiais pelo autor empírico. Tal traço é bastante característico da contística cortazariana em geral, incluindo, sem sombra de dúvidas, $L a$ isla a mediodía. As informações que são ocultadas geram em qualquer narrativa uma espécie de conflito, desconforto ou, até mesmo, confusão. Para Cortázar, ao escrever um conto, esse recurso se faz necessário, pois é preciso escolher as palavras certas, tendo em vista o pouco espaço que há para dizer tudo o que se gostaria. Na reflexão que Cortázar (1977) propõe em seu ensaio Algunos aspectos del cuento, refere que numa fotografia ou num conto, o fotógrafo e o contista se veem obrigados a escolher, diante de uma imagem ou um fato, aquilo que consideram mais significativo frente ao contexto que estão expondo. Tanto no conto quanto na fotografia, o não dito ou o invisível agem no leitor ou no espectador de modo a inquietá-lo e desacomodá-lo. Desde o ponto de vista cortazariano, é necessário provocar tensão num conto, independentemente de seu tema, aspecto esse que também existe na fotografia, de acordo com Javier Marzal Felici. Essa tensão seria responsável pelo dinamismo e equilíbrio da composição. Diante de uma comparação mais geral entre fotografia e conto sob o aspecto da tensão, em La isla a mediodía, o desconforto ocorre em vários momentos da narrativa, em alguns deles por informações que não são reveladas e, além disso, pelo tom fantástico que atravessa a narrativa.

Para finalizar, cabe reforçar a ideia de que, nesta análise, deixamos de abordar inúmeros aspectos de La isla a mediodía, pois não seriam coerentes com o foco que escolhemos dar. A relação que aparece no conto, de Marini com Klaios e seus filhos, por exemplo, se apoiam sobre outro patamar que não, necessariamente, o fotográfico e, dessa forma, optamos por não discuti-la. Assim como o contista e o fotógrafo precisam fazer escolhas no sentido de registrar apenas o que lhes parece significativo no momento da escrita, neste trabalho, a escolha foi a de dar ênfase, prioritariamente, aos aspectos que apresentassem relação com o contexto fotográfico.

\section{REFERÊNCIAS}

ALAZRAKI, Jaime. Qué es lo neofantástico. In: Mester, Vol. 19, N. 2. 1990. Pág. $21-35$. 
192 | Michele Savaris

APENAS. In: DICCIONARIO Real Academia Española. Madrid, 2017. Disponível em 〈www.rae.es $\rangle$. Acesso em: 28 de jan. 2018.

AUMONT, Jacques. A imagem. Tradução: Estela do Santos Abreu e Claudio C. Santoro. São Paulo: Papirus, 1993.

BARTHES, Roland. A câmara clara. Tradução de Julio Castañon Guimarães. Rio de Janeiro: Nova Fronteira, 1984.

BERNÁRDEZ, Aurora; ÁlVAREZ GARRIGA, Carles (orgs). Cortázar de la A a la Z - Un álbum biográfico. Buenos Aires: Aguilar, Altea, Taurus, Alfaguara, 2014.

CORTÁZAR, Julio. A prosa do observatório. Tradução: Davi Arrigucci Júnior. São Paulo: Editora Perspectiva, 1974.

. Las babas del diablo. In: Las armas secretas. Buenos Aires: Editorial Sudamericana, 1971.

. La isla a mediodía. In: Todos los fuegos el fuego. Buenos Aires: Punto de lectura, 2004.

. A ilha ao Meio-Dia. In: Todos os fogos o fogo. 2a Ed. Tradução: Gloria Rodrígues. Rio de Janeiro: Civilização Brasileira, 1974.

- Algunos aspectos del cuento. In: BENEDETTI, M. et al. Literatura y arte nuevo en Cuba. Barcelona: Laia, 1977.

CORTÁZAR, Julio. In: CRESPO, Antonio L. Confieso que he vivido y otras entrevistas. Argentina: LC Editor, 1995.

CORTÁZAR, Julio. Rayuela. Edición crítica, Julio Ortega y Saúl Yurkievich (Coord.). 2a ed. Madrid; París; México; Buenos Aires; São Paulo; Rio de Janeiro; Lima: ALLCA XX, 1996.

FELICI, Javier Marzal. Cómo se lee una fotografia - interpretaciones de la mirada. Madrid: Ediciones Cátedra, 2011.

LA NACIÓN. Julio Cortázar - Compromiso y fantasía. Buenos Aires: Aguilar, Altea, Taurus, Alfaguara, 2006.

MATURO, Graciela. Julio Cortázar: razón y revelación. Ciudad Autónoma de Buenos Aires: Editorial Biblos, 2014.

PIGLIA, Ricardo. Teses sobre o conto. In: O laboratório do escritor. Tradução:Josely Vianna Baptista. São Paulo: Editora Iluminuras, 1994.

PREGO, Omar. O fascínio das palavras - entrevistas com Julio Cortázar. Tradução: Eric Nepomuceno. Rio de Janeiro: José Olympio, 1991.

SEÑAS. Apenas. In: SEÑAS, Diccionario para la Enseñanza de la Lengua Española para Brasileños. São Paulo: Martins Fontes, 2002.

TOMASI, Diego. Cortázar por Buenos Aires, Buenos Aires por Cortázar. Ciudad Auntónoma de Buenos Aires: Seix Barral, 2013. 
Traços da linguagem fotográfica em La isla a mediodía | 193

WOOD, James. Como funciona a ficção. Tradução: Denise Bottmann. São Paulo: Cosac Naify, 2011.

Recebido em: 13/02/2018

Aceito em: 25/03/2018 